\title{
Repair of Parastomal Hernias with Biologic Grafts: A Systematic Review
}

\author{
Nicholas Jonathan Slater • Bibi M. E. Hansson • \\ Otmar R. Buyne $\cdot$ Thijs Hendriks • Robert P. Bleichrodt
}

Received: 22 December 2010 / Accepted: 26 January 2011 /Published online: 1 March 2011

(C) The Author(s) 2011. This article is published with open access at Springerlink.com

\begin{abstract}
Background Biologic grafts are increasingly used instead of synthetic mesh for parastomal hernia repair due to concerns of synthetic mesh-related complications. This systematic review was designed to evaluate the use of these collagen-based scaffolds for the repair of parastomal hernias.

Methods Studies were retrieved after searching the electronic databases MEDLINE, EMBASE and Cochrane CENTRAL. The search terms 'paracolostomy', 'paraileostomy', 'parastomal', 'colostomy', 'ileostomy', 'hernia', 'defect', 'closure', 'repair' and 'reconstruction' were used. Selection of studies and assessment of methodological quality were performed with a modified MINORS index. All reports on repair of parastomal hernias using a collagen-based biologic scaffold to reinforce or bridge the defect were included. Outcomes were recurrence rate, mortality and morbidity.

Results Four retrospective studies with a combined enrolment of 57 patients were included. Recurrence occurred in $15.7 \%$ (95\% confidence interval [CI] 7.8-25.9) of patients and wound-related complications in $26.2 \%$ (95\% CI $14.7-39.5$ ). No mortality or graft infections were reported.

Conclusions The use of reinforcing or bridging biologic grafts during parastomal hernia repair results in acceptable rates of recurrence and complications. However, given the similar rates of recurrence and complications achieved using synthetic mesh in this scenario, the evidence does not support use of biologic grafts.
\end{abstract}

Keywords Biologic graft · Allograft · Xenograft .

Parastomal hernia

\section{Introduction}

Parastomal herniation is a common complication following creation of an ileostomy or colostomy, with observed rates of up to $28 \%$ and $48 \%$, respectively. ${ }^{1}$ Besides risk of incarceration and stenosis of the bowel, parastomal herniation can

N. J. Slater $(\bowtie) \cdot$ O. R. Buyne $\cdot$ T. Hendriks $\cdot$ R. P. Bleichrodt Department of Surgery,

Radboud University Nijmegen Medical Centre, PO Box 9101, 6500 HB, Nijmegen, The Netherlands e-mail: n.slater@chir.umcn.nl

B. M. E. Hansson

Department of Surgery, Canisius-Wilhelmina Hospital,

PO Box 9015, 6500 GS, Nijmegen, The Netherlands cause pain, discomfort and an ill-fitting pouching system that in turn may cause leakage and skin excoriation. Needless to say, body image is adversely affected in patients that might already be experiencing social problems associated with the presence of a stoma. ${ }^{2}$ Surgical treatment modalities available are relocation of the stoma and repair of the defect using either direct suture repair, or bridging or reinforcement with prostheses. Relocation of the stoma does not address tissue weakness secondary to systemic risk factors and, just like direct suture repair, often results in high recurrence rates. ${ }^{3,4}$ Since the introduction of synthetic mesh to reinforce or bridge the defect, this procedure has been regarded as the best possible care for parastomal herniation, showing lower recurrence rates. ${ }^{1,5}$ Its prophylactic use at the time of initial stoma creation is now often propagated to prevent future herniation. ${ }^{5,6}$ At the same time, reservations have arisen with respect to the implantation of synthetic mesh in close proximity to bowel and stoma due to risk of erosion and fistula formation. ${ }^{7}$ Also, dense adhesions may complicate 
future abdominal surgery. ${ }^{8}$ Besides these concerns, there is the universal fear of infection when implanting foreign body material, especially in contaminated fields.

Collagen-based biologic grafts have been produced since the 1980s. ${ }^{9}$ These prostheses consist of an acellular collagen matrix that is slowly degraded and replaced by fibrocollagenous tissue of the host. Their properties depend on the species and type of tissue that the material is extracted from, the processing methods (including decellularisation and sterilisation), and whether or not they are intentionally crosslinked. Biologic grafts used for incisional hernia repair are derived from either human dermis, porcine dermis, porcine small intestinal submucosa, or bovine pericardium. During processing, the materials are made functionally acellular to prevent a foreign body response, while still maintaining their extracellular collagenous structure that allows for the host tissue ingrowth. Sterilisation of the materials by ethylene oxide gas or irradiation aims at making the final product pathogen free. Some products receive additional cross-linking of the collagen matrix to control or reduce the enzymatic degradation of the graft. This should give the host more time to deposit fibro-collagenous tissue and remodel the prosthesis into strong native tissue. Due to their bio-compatibility resulting in rapid vascularisation and migration of host (immune) cells, it is thought that biologic prostheses are less prone to infection than synthetic grafts. Moreover, they are soft and pliable which potentially decreases the risk of discomfort and erosion into the bowel. However, given the high financial costs of biologic grafts, proper evidence of more beneficial outcomes or cost savings in the long run are paramount to support their use. This systematic review aims to evaluate the use of these acellular collagen-based scaffolds for the repair of parastomal hernias, focusing on recurrence and complication rates.

\section{Methods}

Search Methods for Study Identification

Studies were identified using the electronic databases MEDLINE (including in-process and other non-indexed citations, 1950-present), EMBASE (1980-present) and the Cochrane Central Register of Controlled Trials. Search terms used were: 'parastomal', 'paracolostomy', 'paraileostomy', 'stoma', 'hernia', 'defect' and 'repair'. Terms were searched for as free text and where applicable were also mapped to MeSH terms. Full-text articles retrieved for evaluation were scanned for other relevant references. No limits were set on language or publication status. Titles and abstracts were screened for eligibility and full-text articles were retrieved. The last search was performed on 13 September 2010. All reports on repair of parastomal hernias using a acellular collagen-based biologic scaffold as sole material to reinforce or bridge the defect were included. All other types of repair were excluded.

\section{Assessment of Study Quality}

All studies selected were subjected to a modified version of the Methodological Index for Non-Randomised Studies (MINORS) tool to evaluate their methodological quality (Table 1). This instrument was constructed and validated
Table 1 Modified Methodological Index of Non-Randomised Studies (MINORS)

\begin{tabular}{llll}
\hline Item & Criteria & Option & Score \\
\hline 1 & A clearly stated aim & Not reported & 0 \\
& & Partially reported, no clear aim & 1 \\
& & Clear aim & 2 \\
2 & Minimum of 5 included patients & No & 0 \\
& & Yes & 2 \\
3 & Inclusion of consecutive patients & Not reported & 0 \\
& & Patients in a certain time period & 1 \\
& & Consecutive patients +characteristics & 2 \\
4 & Type of stoma specified & Not reported & 0 \\
& & Reported & 2 \\
5 & Surgical technique reported & Not reported & 0 \\
& & Incomplete & 1 \\
& & Reported clearly, appropriate to aim & 2 \\
& & Not reported & 0 \\
& & Recurrences only & 1 \\
& & Recurrences and postoperative complications & 2 \\
& & Maximum score: & 12 \\
\hline
\end{tabular}


for appraisal of non-randomised trials in surgery. ${ }^{10}$ Studies were scored independently by two authors (NJS, RPB). This modified version contains six items with a maximum score of two on each, yielding a maximum index of 12 . Studies with a total score less than nine, or no score on item 2, 5 or 6 were excluded from systematic review. Disagreement was resolved by discussion and consensus between authors. Also, the diagnostic modality for the primary outcome was determined for every study.

\section{Data Extraction}

The primary outcome was the rate of parastomal hernia recurrence observed, as defined by the respective authors. Study characteristics (year of publication, no. of patients, surgical technique, follow-up), perioperative (30 days) mortality and rates and type of wound-related complications were also noted. Total amount of wound-related complications were calculated by adding up all relevant complications, including only the studies with adequate reporting. Weighted pooled proportions with their respective $95 \%$ confidence intervals (CI) following the fixed-effects (inverse variance) model were determined for recurrences and wound-related complications using StatsDirect ${ }^{\circledR}$ statistical software. ${ }^{11}$

\section{Results}

A flowchart overview of the search is depicted in Fig. 1. The search strategy yielded 333 titles and abstracts. After screening, 317 records were excluded leaving 16 articles to be retrieved and assessed for eligibility. Six of these were

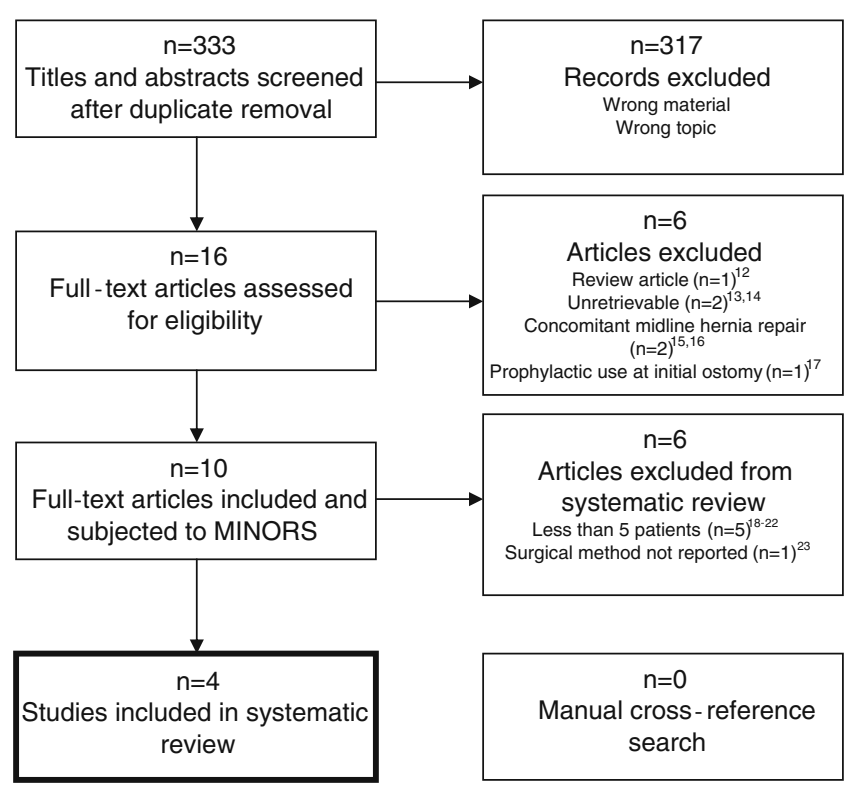

Fig. 1 Flowchart of search strategy excluded after assessment ${ }^{12-17}$ leaving a total of 10 articles that reported on the repair of parastomal hernias with biologic prostheses. After subjecting these to the modified MINORS tool, another six were excluded due to too small sample sizes ${ }^{18-22}$ and inadequate reporting on surgical technique. ${ }^{23}$ This left four studies to be included in the systematic review. ${ }^{24-27}$

\section{Findings of Systematic Review}

All included studies were retrospective with a combined enrolment of 57 patients (range 11-20). The definition of a recurrence was not given by any author. Follow-up ranged from 8.1 to 50.2 months, and was done by clinical examination in three ${ }^{25-27}$ and also by CT imaging in one. ${ }^{26}$ One study was unclear as to how follow-up was performed. ${ }^{24}$ No mortality was reported. Study characteristics and outcomes including weighted pooled rates of recurrence and wound-related complications are shown in Table 2. The weighted pooled proportion of recurrences was $15.7 \%$ (95\% CI 7.8-25.9; Fig. 2). No cases of infected grafts were reported. Araujo et al. only reported on infection (which was absent) and therefore their data were not included in the calculation of wound-related complications. Various surgical techniques were used, including onlay, inlay, and underlay (pre- and intraperitoneal) placement of the biologic graft. Both open and laparoscopic procedures were performed. Biologic grafts used were products derived from human acellular dermis (Allo$\operatorname{derm}^{\circledR}$ ), bovine pericardium (Peri-Guard ${ }^{\circledR}$ ) and porcine small intestinal submucosa $\left(\right.$ Surgisis $\left.^{\circledR}\right)$. Characteristics of the biologic grafts used in the included and excluded studies are given in Table 3.

\section{Studies Excluded From Systematic Review}

Six reports on the use of biologic grafts for the repair of parastomal hernias were excluded after subjecting them to the modified MINORS tool, including retrospective studies, ${ }^{20,23}$ case reports ${ }^{19,21}$ and case series ${ }^{18,22}$ (Table 4). Two case reports and two case series described the use of biologic grafts for the repair of parastomal hernia. Greenstein and Aldoroty ${ }^{19}$ reported on a patient with a history of ulcerative colitis and four ileostomy revisions that presented with unremitting obstructive symptoms. An incarcerated parastomal hernia confirmed by $\mathrm{CT}$ was repaired using cross-linked porcine dermis (Collamend $\left.{ }^{\circledR}\right)$ in a retromuscular fashion. Patient regained ileostomy function within a few days and when seen at 18 months was pain free with no evidence of graft infection, hernia recurrence, ileostomy malfunction or obstruction. Lo Menzo et al. ${ }^{21}$ reported on a patient with a history of abdominoperineal resection for rectal cancer that presented with a three-time 
Table 2 Study characteristics and recurrence rates of studies included in systematic review

\begin{tabular}{|c|c|c|c|c|c|c|c|c|}
\hline Reference & Year & $\begin{array}{l}\text { No. of } \\
\text { patients }\end{array}$ & $\begin{array}{l}\text { MINORS } \\
\text { index }\end{array}$ & Material used & Type of repair & $\begin{array}{l}\text { No. of wound } \\
\text { complications (\%) }\end{array}$ & Recurrence (\%) & $\begin{array}{l}\text { Months } \\
\text { follow-up } \\
\text { (range) }\end{array}$ \\
\hline Araujo et al. ${ }^{24}$ & 2005 & 13 & 10 & Peri-Guard & Onlay & $\mathrm{n} / \mathrm{a}$ & $1(7.7)$ & $50.2(\mathrm{n} / \mathrm{a})^{\mathrm{a}}$ \\
\hline Aycock et al. ${ }^{25}$ & 2007 & 11 & 9 & Alloderm & $\begin{array}{l}\text { Inlay }(n=8) \text { and onlay } \\
(n=3)\end{array}$ & $2(18.2)$ & $3(27.3)$ & $8.1(1-21)$ \\
\hline Taner et al. ${ }^{26}$ & 2009 & 13 & 9 & Alloderm & Under+onlay sandwich & $5(38.5)$ & $2(15)$ & $9(4-16)$ \\
\hline Ellis $^{27}$ & 2010 & 20 & 12 & Surgisis & $\begin{array}{l}\text { Intraperitoneal underlay } \\
\text { (Sugarbaker) }\end{array}$ & $4(20.0)$ & $2(10)$ & $18(6-38)$ \\
\hline $\begin{array}{l}\text { Weighted pooled } \%{ }^{\mathrm{c}} \\
(95 \% \mathrm{CI})\end{array}$ & - & - & - & - & - & $26.2 \%(14.7-39.5)$ & $15.7 \%(7.8-25.9)$ & - \\
\hline
\end{tabular}

${ }^{a}$ This follow-up is that of a larger group of which these patients were part of

${ }^{\mathrm{b}}$ Complications: wound infection (3), ${ }^{5,26}$ seroma formation (6), ${ }^{26,27}$ incisional separation (2) ${ }^{26}$

${ }^{\mathrm{c}}$ Using a fixed-effects (inverse variance) model

recurrent parastomal hernia, for which an expanded polytetrafluoroethylene mesh was used for the last repair using the keyhole technique. The Sugarbaker technique ${ }^{28}$ was employed using bovine pericardium (Veritas ${ }^{\circledR}$ ). Postoperatively, a seroma developed which resolved spontaneously; and at 17-month follow-up, there was no evidence of recurrence, the patient was pain free and satisfied with cosmetic results. In a case series of three patients, Kish et al. ${ }^{22}$ reported on the primary repair of parastomal hernia using human acellular dermis (Alloderm) as onlay reinforcement. Two patients were followed for 6 months and 1 year, respectively, and remained hernia free. One patient presented 8 months later with symptoms of intestinal obstruction treated conservatively. The patient subsequently returned 3 months later with intestinal obstruction and recurrent parastomal hernia that necessitated an operation for relocation of the stoma and repeat hernia repair. Inan et al. ${ }^{18}$ reported on two patients, one with a history of proctectomy after severe radiation proctitis presenting with discomfort and obstructive episodes, the other presenting with symptomatic hernia 18 years after abdominoperineal resection. Both were repaired laparoscopically using cross-linked porcine dermis $\left(\right.$ Permacol $\left.^{\circledR}\right)$, and at 9 and 3 months postoperatively there was no evidence of recurrence or mesh-related complications.

Two retrospective studies on the use of cross-linked porcine dermis (Permacol) for various types of hernia repair in complex, infected or potentially contaminated settings, included six patients undergoing parastomal hernia repair. Of the total of 133 procedures, Franklin et al. ${ }^{23}$ repaired parastomal hernia using intraperitoneal onlay mesh in two patients, showing no recurrences. ${ }^{20}$ Follow-up ranged 178 months using clinical examination. Loganathan et al. ${ }^{23}$ reported on repair of four parastomal hernias, one of which underwent reversal of the colostomy at the time of the hernia repair. Of the other three patients, one that had six
Fig. 2 Weighted pooled proportion (fixed-effects model; Cochran's $Q=1.917, p=0.5899$ ) of recurrences after parastomal hernia repair using biologic grafts

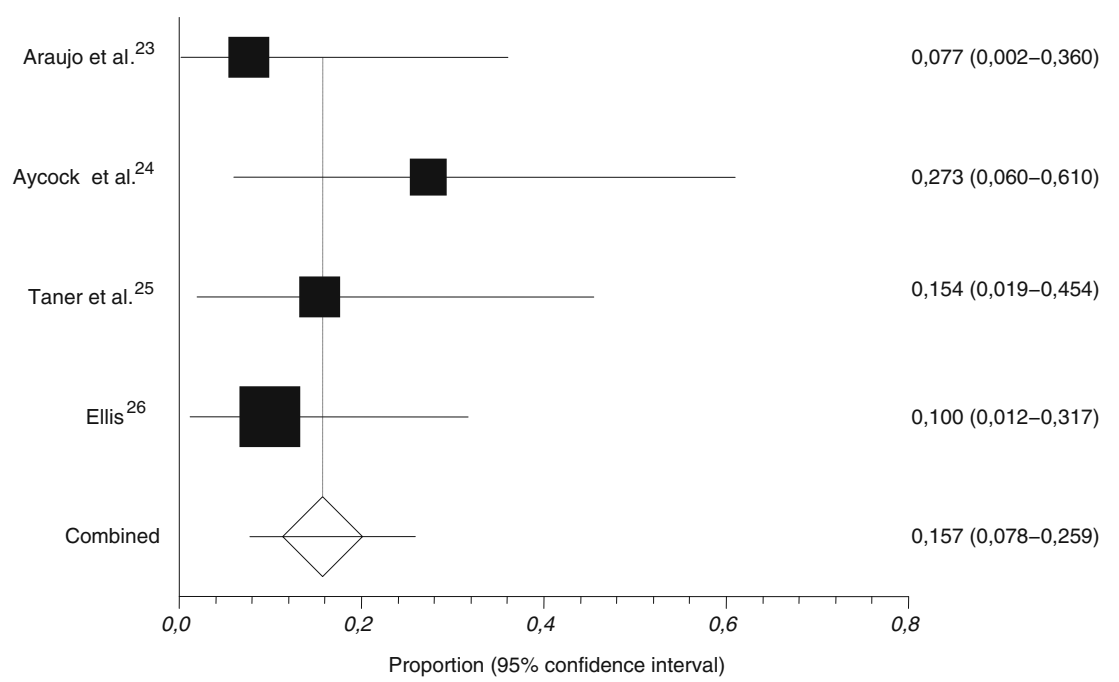


Table 3 Characteristics and costs of biologic and synthetic prostheses used for parastomal hernia repair

\begin{tabular}{lllll}
\hline Material & Source & Additional cross-linking & Preparation & Costs per cm $^{2 \mathrm{a}}$ \\
\hline Alloderm & Human dermis & None & Refrigeration, rehydration & $\$ 35.31$ \\
Permacol & Porcine dermis & Yes; HMDI & None & $\$ 18.97$ \\
Surgisis & Porcine SIS & None & Rehydration & $\$ 20.00$ \\
Collamend & Porcine dermis & Yes; EDC & Rehydration & $\$ 18.88$ \\
Peri-guard & Bovine pericardium & Yes; gluteraldehyde & Rehydration & $\$ 3.91$ \\
Veritas & Bovine pericardium & None & None & $\$ 22.02$ \\
& Polypropylene/e-PTFE/Composite & - & None & $\$ 3.65$ \\
\hline
\end{tabular}

${ }^{a}$ Based on sheet sizes sufficient for parastomal hernia repair, excluding account discount. Manufacturers and distributors were contacted directly via telephone

SIS small intestinal submucosa; HMDI hexamethylene diisocyanate; EDC 1-ethyl-(3-dimethylaminopropyl) carbodiimide hydrochloride; Alloderm LifeCell Corp., Branchburg, NJ, USA; Permacol Tissue Science Laboratories, Aldershot, UK; Surgisis Cook Surgical, Bloomington, IN, USA; Collamend Bard Inc., Warwick, RI, USA; Xenmatrix Brennen Medical Inc., St. Paul, MN, USA; Veritas, Peri-Guard Synovis Surgical Innovations, St. Paul, MN, USA

previous attempts at hernia repair experienced a recurrence. This patient developed an ischaemic end ileostomy which subsequently developed a localised perforation which manifested as a fistula formation. Another patient also developed a fistula. Cross-linked porcine dermis (Permacol) was placed as inlay or onlay. Median follow-up of the complete series was 377 days (range 85-1,905 days) performed by clinical examination.

\section{Discussion}

The current systematic review evaluated the use of biologic grafts for parastomal hernia repair, which results in acceptable rates of recurrence, with a pooled rate of $15.7 \%$ (95\% CI 7.8-25.9). Wound-related complications were reported in $26.2 \%$ (95\% CI 14.7-39.5). Given the current evidence, biologic grafts do not provide a superior alternative to other surgical options.
In their review on parastomal hernia from 2003, Carne et al. ${ }^{1}$ shed some light on the outcomes of different techniques of parastomal hernia repair. In studies using synthetic meshes (intraperitoneal, preperitoneal and fascial onlay), the overall recurrence rate was $6 / 77(7.8 \%)$. Infection is uncommon and only infrequently requires removal of the mesh. A search of the literature published since reveals reherniation occurring in 62/371 (16.7\%) patients. ${ }^{29-42}$ As found by Carne et al., complications were low, with mesh infection reported in 15/460 (3\%) of the patients. In the current systematic review of parastomal hernia repair using biologic grafts, rates of recurrence ranged from $7.7 \%$ to $27.3 \%$, with a weighted pooled average of $15.7 \%(95 \% \mathrm{CI}$ 7.8-25.9). Graft infection was zero, and other woundrelated complications including wound infection were $26.2 \%$ (95\% CI 14.7-39.5). Thus, these rates are very similar to those found for synthetic mesh. Notably, even the risk of mesh infection appears to be low when a synthetic graft is implanted. Given the current evidence, it cannot be

Table 4 Study characteristics and recurrence rates of studies excluded from systematic review

\begin{tabular}{|c|c|c|c|c|c|c|c|}
\hline Reference & Year & $\begin{array}{l}\text { No. of } \\
\text { patients }\end{array}$ & $\begin{array}{l}\text { Material } \\
\text { used }\end{array}$ & Type of repair & $\begin{array}{l}\text { No. of wound } \\
\text { complications }(\%)^{b}\end{array}$ & Recurrence $(\%)$ & $\begin{array}{l}\text { Follow-up } \\
\text { (range) }\end{array}$ \\
\hline Kish et al. ${ }^{22}$ & 2005 & 3 & Alloderm & Onlay & $\mathrm{n} / \mathrm{a}$ & $1(33.3)$ & $(6-12)$ \\
\hline $\operatorname{Inan}^{18}$ & 2007 & 2 & Permacol & Laparoscopic (method not specified) & $\mathrm{n} / \mathrm{a}$ & $0(0)$ & $6(3-9)$ \\
\hline Greenstein \& Aldoroty ${ }^{19}$ & 2008 & 1 & Collamend & Retromuscular/sublay & $0(0)$ & $0(0)$ & 18 \\
\hline Franklin et al. $^{20}$ & 2008 & 2 & Surgisis & $\begin{array}{l}\text { Intraperitoneal onlay mesh } \\
\text { (Laparoscopic) }\end{array}$ & $\mathrm{n} / \mathrm{a}$ & $0(0)$ & $\mathrm{n} / \mathrm{a}$ \\
\hline Lo Menzo et al. ${ }^{21}$ & 2008 & 1 & Veritas & $\begin{array}{l}\text { Intraperitoneal (Laparoscopic } \\
\text { Sugarbaker) }\end{array}$ & $1(100)$ & $0(0)$ & 17 \\
\hline Loganathan et al. ${ }^{23}$ & 2010 & 3 & Permacol & $\mathrm{n} / \mathrm{a}$ & $2(66)$ & $1(33)$ & $12(3-62)^{\mathrm{a}}$ \\
\hline
\end{tabular}

${ }^{a}$ This follow-up is that of a larger group of which these patients were part of

${ }^{\mathrm{b}}$ Complications: seroma formation (1), ${ }^{21}$ ischaemic ileostomy and subsequent fistula (1), ${ }^{23}$ fistula (1) ${ }^{23}$ 
concluded that biologic prostheses are more preferable than synthetic mesh to reduce the rates of immediate or long-term complications. Moreover, biologic grafts are very expensive compared to synthetic mesh (Table 3), which further refutes their superiority over synthetic mesh to provide not only effective but also efficient and cost-effective healthcare. With limited financial resources, careful consideration must be taken whilst choosing the types of materials to use.

It is well established that parastomal hernias can occur after great periods of time. Also, on the long run, risk of infection may remain higher for non-absorbable synthetic meshes compared to degradable biologic grafts due to a prolonged presence of foreign body material. Studies with longer follow-up are therefore imperative to yield more reliable rates of recurrence and late complications for both these treatment modalities. The results of this systematic review were troubled by typical issues of potential bias, including the lack of uniformity between studies in definition and reporting of outcomes and patient characteristics.

Given the scarcity of relevant studies, combined with the variety of biologic grafts used, it is impossible to make a direct comparison between the different products or types of material. The same goes for the surgical technique used (i.e. the type of prosthetic placement), which is also of relevance for outcome. With synthetic meshes, average rates of recurrence after sublay mesh $(5.7 \%)^{34,39}$ and intraperitoneal mesh $(11.1 \%)^{32,33}$ are lower than after onlay mesh $(22.8 \%)^{29-31}$ or laparoscopically placed intraperitoneal mesh (16.6\%). ${ }^{35-38,40-42}$ Onlay placement requires extensive dissection of subcutaneous tissue which predisposes for hematoma and seroma formation and may disrupt skin vascularisation leading to impaired wound healing. Moreover, due to its anatomical position, intra-abdominal pressure may lead to lateral detachment of the graft resulting in its higher recurrence rates. On the other hand, sublay and underlay techniques theoretically benefit from the intra-abdominal pressures which may help to keep the graft in place. Concerning complications, the sublay placement again theoretically seems the most advantageous of the techniques, resulting in the least contact between mesh and bowel.

Besides its use for the repair of parastomal hernia, there has been much debate as to the effectiveness of the prophylactic placement of a reinforcing prosthesis at the time of initial stoma formation. In a recent systematic review of the use of a mesh to prevent parastomal hernia, Tam et al. ${ }^{6}$ made a strong case for the use of prophylactic mesh at the time of initial stoma formation, showing an overall recurrence rate of $15.4 \%$, compared to $55.2 \%$ in patients who received a conventional stoma. Their meta-analysis performed on three randomised controlled trials yielded similar results. Complications were very low and did not differ between the two groups. To date, only one study can be identified that used a biologic graft for this purpose. ${ }^{17}$ Hammond et al. compared the prophylactic use of cross-linked porcine dermis (Permacol) to conventional stoma formation. After a median follow-up of only 6.5 months, the conventional group had a recurrence rate of $33.3 \%$, while the prophylactic group showed no recurrences. No complications were observed. Given the very low rate of complications associated with prophylactic synthetic mesh placement, there is as yet no support for the use of biologic grafts instead of synthetic ones in this surgical scenario.

As mentioned earlier, when studying rates of hernia recurrence, next to an appropriate follow-up a properly defined outcome measure is deemed essential to create uniform and comparable findings. None of the studies in the current review provided a proper definition of a recurrence. Most studies used clinical examination to detect hernias, and one study also used CT imaging in all patients. ${ }^{26}$ Here, the two patients that had radiologic evidence of a recurrence continued to be asymptomatic at 385 and 509 days follow-up, respectively, requiring no revision of their repair. Another study, which was excluded from this review due to the prophylactic placement of a biologic graft, also used CT imaging in all patients to determine hernia occurrence. ${ }^{16}$ Similarly, the only two occurrences were found on CT scan and were small asymptomatic hernias. If these studies had used only clinical examination, it is conceivable that these asymptomatic patients might not have been found to have a recurrence. Most recently, Gurmu et al. examined the inter-observer reliability of clinical examination of parastomal hernia in three hospitals. ${ }^{43}$ This appeared to be low, with kappa values ranging between 0.29 and 0.73 . The correlation between CT and patient-reported complaints using a colostomy questionnaire was also low, revealing a kappa of 0.45 . Even though the underestimation of rates of (minor) parastomal hernias may well be very common, its clinical relevance in asymptomatic and satisfied patients is only manifest in an increased risk of complications due to the hernia, such as incarceration and stenosis of bowel. It is hard to estimate these risks in patients with asymptomatic or small hernias, but given the marginal amount of recurrences and long-term complications in the studies discussed in this review and in the literature, they do not seem to give cause for concern.

Conflict of interest None of the authors have a conflict of interest or financial tie to disclose.

Open Access This article is distributed under the terms of the Creative Commons Attribution Noncommercial License which permits any noncommercial use, distribution, and reproduction in any medium, provided the original author(s) and source are credited.

\section{References}

1. Carne PW, Robertson GM, Frizelle FA. Parastomal hernia. $\mathrm{Br} J$ Surg. 2003;90: 784-793. 
2. Cheung MT. Complications of an abdominal stoma: an analysis of 322 stomas. Aust N Z J Surg. 1995;65: 808-811.

3. Rubin MS, Schoetz DJ Jr, Matthews JB. Parastomal hernia. Is stoma relocation superior to fascial repair? Arch Surg. 1994;129: 413-418.

4. Riansuwan W, Hull TL, Millan MM, Hammel JP. Surgery of recurrent parastomal hernia: direct repair or relocation? Colorectal Dis. 2010;12:681-6.

5. Israelsson LA. Preventing and treating parastomal hernia. World $J$ Surg. 2005;29: 1086-1089.

6. Tam KW, Wei PL, Kuo LJ, Wu CH. Systematic review of the use of a mesh to prevent parastomal hernia. World J Surg. 2010; 34 (11):2723-2729.

7. Aldridge AJ, Simson JNL. Erosion and perforation of colon by synthetic mesh in a recurrent paracolostomy hernia. Hernia. 2001;5: 110-112.

8. Morris-Stiff G, Hughes LE. The continuing challenge of parastomal hernia: failure of a novel polypropylene mesh repair. Ann $R$ Coll Surg Engl. 1998;80: 184-187.

9. Decurtins M, Buchmann P. Bovine pericardium-a new graft material for hernial repair. Res Exp Med (Berl.) 1982;180: 11-14.

10. Slim K, Nini E, Forestier D, Kwiatkowski F, Panis Y, Chipponi J. Methodological index for non-randomized studies (MINORS): development and validation of a new instrument. ANZ J Surg. 2003;73: 712-761.

11. StatsDirect statistical software [computer program]. Version 2.7.8. England: StatsDirect Ltd; 2008.

12. Hiles M, Record Ritchie RD, Altizer AM. Are biologic grafts effective for hernia repair? A systematic review of the literature. Surg Innov. 2009;16: 26-37.

13. Wietfeldt ED, Hassan I, Rakinic J. Utilization of bovine acellular dermal matrix for abdominal wall reconstruction: a retrospective case series. Ostomy Wound Manage. 2009;55: 52-56.

14. Pullan R., Defriend D. Colorectal Dis 2009 Sep;11 Suppl 2:1-57. Abstracts of the Fourth Annual Meeting of the European Society of Coloproctology. September 23-26, 2009. Prague, Czech Republic.

15. Liyanage SH, Purohit GS, Frye JN, Giordano P. Anterior abdominal wall reconstruction with a Permacol implant. $J$ Plast Reconstr Aesthet Surg. 2006;59: 553-555.

16. Rosen MJ, Reynolds HL, Champagne B, Delaney CP. A novel approach for the simultaneous repair of large midline incisional and parastomal hernias with biological mesh and retrorectus reconstruction. Am J Surg. 2010;199: 416-420.

17. Hammond TM, Huang A, Prosser K, Frye JN, Williams NS. Parastomal hernia prevention using a novel collagen implant: a randomised controlled phase 1 study. Hernia. 2008;12: 475481.

18. Inan I, Gervaz P, Hagen M, Morel P. Multimedia article. Laparoscopic repair of parastomal hernia using a porcine dermal collagen (Permacol) implant. Dis Colon Rectum. 2007;50: 1465.

19. Greenstein AJ, Aldoroty RA. Parastomal hernia repair using cross-linked porcine dermis: report of a case. Surg Today. 2008;38: 1048-1051.

20. Franklin ME Jr, Treviño JM, Portillo G, Vela I, Glass JL, González JJ. The use of porcine small intestinal submucosa as a prosthetic material for laparoscopic hernia repair in infected and potentially contaminated fields: long-term follow-up. Surg Endosc. 2008;22: 1941-1946.

21. Lo Menzo E, Martinez JM, Spector SA, Iglesias A, Degennaro V, Cappellani A. Use of biologic mesh for a complicated paracolostomy hernia. Am J Surg. 2008;196: 715-719.
22. Kish KJ, Buinewicz BR, Morris JB. Acellular dermal matrix (AlloDerm): new material in the repair of stoma site hernias. $\mathrm{Am}$ Surg. 2005;71: 1047-1050.

23. Loganathan A, Ainslie WG, Wedgwood KR. Initial evaluation of Permacol bioprosthesis for the repair of complex incisional and parastomal hernias. Surgeon. 2010; 8: 202-205.

24. Araujo SE, Habr-Gama A, Teixeira MG, Caravatto PP, Kiss DR, Gama-Rodrigues J. Role of biological mesh in surgical treatment of paracolostomy hernias. Clinics (Sao Paulo). 2005;60: 271-276.

25. Aycock J, Fichera A, Colwell JC, Song DH. Parastomal hernia repair with acellular dermal matrix. $J$ Wound Ostomy Continence Nurs. 2007;34: 521-523.

26. Taner T, Cima RR, Larson DW, Dozois EJ, Pemberton JH, Wolff BG. The use of human acellular dermal matrix for parastomal hernia repair in patients with inflammatory bowel disease: a novel technique to repair fascial defects. Dis Colon Rectum. 2009;52: 349-354.

27. Ellis CN. Short-term outcomes with the use of bioprosthetics for the management of parastomal hernias. Dis Colon Rectum. 2010;53: 279-283.

28. Sugarbaker PH. Prosthetic mesh repair of large hernias at the site of colonic stomas. Surg Gynecol Obstet. 1980;150: 576-578.

29. Steele SR, Lee P, Martin MJ, Mullenix PS, Sullivan ES. Is parastomal hernia repair with polypropylene mesh safe? Am $J$ Surg. 2003;185: 436-440.

30. Ho KMT, Fawcett DP. Parastomal hernia repair using the lateral approach. BJU Int. 2004;94: 598-602.

31. Rieger N, Moore J, Hewett P, Lee S, Stephens J. Parastomal hernia repair. Colorectal Dis. 2004;6: 203-205.

32. Stelzner S, Hellmich G, Ludwig K. Repair of paracolostomy hernias with a prosthetic mesh in the intraperitoneal onlay position: modified Sugarbaker technique. Dis Colon Rectum. 2004;47: 185-191.

33. Van Sprundel TC, Gerritsen van der Hoop A. Modified technique for parastomal hernia repair in patients with intractable stoma care problems. Colorectal Dis. 2005;7: 445-449.

34. Longman RJ, Thompson WH. Mesh repair of parastomal herniasa safety modification. Colorectal Dis. 2005;7: 292-294.

35. LeBlanc KA, Bellanger DE, Whitaker JM, Hausman MG. Laparoscopic parastomal hernia repair. Hernia. 2005;9: 140-144.

36. McLemore EC, Harold KL, Efron JE, Laxa BU, Young-Fadok TM, Heppell JP. Parastomal hernia: short-term outcome after laparoscopic and conventional repairs. Surg Innov. 2007;14: 199-204.

37. Mancini GJ, McClusky DA, Khaitan L et al. Laparoscopic parastomal hernia repair using a nonslit mesh technique. Surg Endosc. 2007;21: 1487-1491.

38. Berger D, Bientzle M. Laparoscopic repair of parastomal hernias: a single surgeon's experience in 66 patients. Dis Colon Rectum. 2007;50: 1668-1673.

39. Guzman-Valdivia G, Guerrero TS, Laurrabaquio HV. Parastomal hernia repair using mesh and an open technique. World J Surg. 2008;32: 465-470.

40. Craft RO, Huguet KL, McLemore EC, Harold KL. Laparoscopic parastomal hernia repair. Hernia. 2008;12: 137-140.

41. Hansson BME, Bleichrodt RP, De Hingh IHJT. Laparoscopic parastomal hernia repair using a keyhole technique results in a high recurrence rate. Surg Endosc. 2009;23: 1456-1459.

42. Pastor DM, Pauli EM, Koltun WA, Haluck RS, Shope TR, Poritz LS. Parastomal hernia repair: a single center experience. JSLS. 2009;13: 170-175.

43. Gurmu A, Matthiessen P, Nilsson S, Påhlman L, Rutegård J, Gunnarsson U. The inter-observer reliability is very low at clinical examination of parastomal hernia. Int J Colorectal Dis. 2010; 26 (1):89-95. 